J. Clin. Chem. Clin. Biochem.

Vol. 16, 1978, pp. 429-434

\title{
Quantitative Determination of the Binding Capacity of the Sex Hormone-Binding Globulin, Using Agar Gel Electrophoresis
}

\author{
By M. Krieg and C. Arning ${ }^{1}$ ) \\ Department of Clinical Chemistry, Medical Clinic, University of Hamburg
}

(Received October 27, 1977/March 25, 1978)

\begin{abstract}
Summary: An easy, rapid and precise technique for the determination of the binding capacity of the sex hormonebinding globulin (SHBG) is described. The plasma is incubated with $\left[{ }^{3} \mathrm{H}\right] 5 \alpha$-dihydrotestosterone (DHT) either alone, or together with an excess of unlabelled DHT. The SHBG-binding peaks are demonstrated by agar gel electrophoresis according to Wagner ((1972) Hoppe-Seylers Z. Physiol. Chem. 353, 1235-1245), and the SHBG-binding capacity is calculated from the radioactivity specifically bound to the SHBG peak, corrected for the dissociation of the $\left[{ }^{3} \mathrm{H}\right]$ DHT from SHBG during the 90 minute electrophoresis. In addition to investigating various problems of methodology, the following clinical results were obtained: 1 . Normal range $(\bar{x} \pm s)$ of the SHBG-binding capacity for males (age $22-41 ; \mathrm{n}=26) 38 \pm 11 \mathrm{nmol} / 1$. 2. An older male group has, with $48 \pm 10 \mathrm{nmol} / 1$, a significantly higher binding capacity. 3 . The highest values found so far were in pregnancy plasma of the third trimenon ( 330 and $400 \mathrm{nmol} / \mathrm{l})$.
\end{abstract}

\section{Quantitative Bestimmung der Bindungskapazität des Sexualhormon-bindenden Globulins mittels Agargelektrophorese}

Zusammenfassung: Beschrieben wird eine einfache, schnelle und präzise Methode zur Bestimmung der Bindungskapazität des Sexualhormon-bindenden Globulins (SHBG). Die Hauptschritte beinhalten die Inkubation des Plasma mit $\left[{ }^{3} \mathrm{H}\right] 5 \alpha$-Dihydrotestosteron (DHT) allein oder zusammen mit einem gegenüber dem tritiierten DHT im Überschuß zugegebenen unmarkierten DHT, die Darstellung des SHBG-Peaks mittels Agargelelektrophorese nach Wagner, sowie die Errechnung der Bindungskapazität des SHBG aufgrund der spezifisch im SHBG-Peak gebundenen Radioaktivität unter Berücksichtigung der Dissoziation von $\left[{ }^{3} \mathrm{H}\right] \mathrm{DHT}$ und SHBG während der 90 -minütigen Elektrophorese. Neben Antworten auf methodische Fragen werden drei klinisch relevante Befunde mitgeteilt: 1. Der Normalbereich $(\bar{x} \pm s)$ der SHBG-Bindungskapazität für Männer (Altersbereich 22-41 Jahre; $n=26$ ) beträgt $38 \pm 11 \mathrm{nmol} / 1$. Eine ältere männliche Probandengruppe hat mit $48 \pm 10 \mathrm{nmol} / \mathrm{l}$ eine signifikant höhere SHBG-Bindungskapazität. 3. Bisher wurden die höchsten Werte (330 und $400 \mathrm{nmol} / \mathrm{l}$ ) im Plasma Schwangerer des dritten Trimenon gefunden.

\section{Introduction}

In 1966 Mercier et al. (1) described a plasma protein which binds testosterone with high affinity. In the same year Rosenbaum et al. (2) found a plasma protein displaying high affinity for estradiol-17 $\beta$. Later, the common identity of both binding proteins was clearly shown by DeMoor et al. (3). In order to understand the physiological role of this sex hormone-binding globulin (SHBG), its quantitative determination is necessary. Most of the respective techniques are based on the same principle:

(a) saturation of the binding sites by tritiated steroids,

(b) followed by separation of the SHBG-bound radioactivity from unspecifically bound and free radioactivity,

1) Part of doctoral thesis; Supported by the DFG, SFB 34 (c) calculation of the SHBG-binding capacity by the amount of SHBG-bound tritiated steroid.

Various procedures have been proposed for the separation of the steroid-SHBG complex, as reviewed very recently by $L u t z$ et al. (4): classical equilibrium dialysis, microdialysis with Sephadex G-25, conventional gel filtration, competitive absorption using dextran-coated charcoal or florisil, and precipitation with ammonium sulphate. Less frequently used in this respect are the polyacrylamide gel electrophoresis $(5,6)$, DAEA-cellulose filter paper (7) and equilibrium partition in an aqueous twophase system (8).

For several years we have used agar gel electrophoresis according to Wagner (9) for the determination of androgen receptors in target tissues $(10,11)$. In an abstract, Wagner \& Rüffert (12) first reported that agar 
gel electrophoresis can also be used for quantifying the SHBG-binding capacity. This technique allows an easy, rapid and precise demonstration of the SHBG- $\left[{ }^{3} \mathrm{H}\right] 5 \alpha$ dihydrotestosterone (DHT) complex, the method therefore being highly suitable as a routine assay for the determination of the SHBG-binding capacity.

The detailed description and evaluation of the technique, the comparison of the data with values obtained by a SHBG-binding capacity determination according to Dennis et al. (10), and the assessment of a normal range of the SHBG-binding capacity in male plasma are the subjects of the report.

\section{Material and Methods}

Heparinized blood was obtained from normal male blood donors. It was immediately centrifuged (20 min at $3000 \mathrm{rpm}$ ) and the plasma stored at $-18^{\circ} \mathrm{C}$.

\section{Chemicals and solutions}

$\left[1,2-{ }^{3} \mathrm{H}\right] 5 \alpha$-Dihydrotestosterone (DHT; specific activity $1628 \mathrm{TBq} / \mathrm{mol}(44 \mathrm{Ci} / \mathrm{mmol})$; purity $96 \%$ ) was obtained from NEN Chemicals (Dreieichenhain). The radioactive steroid in benzene/ethanol $(9+1$, volumes) was evaporated to dryness and the residue was redissolved in physiological $\mathrm{NaCl}$ solution/ ethanol $(9+1$, volumes) to obtain a solution of $57.7 \mathrm{MBq} / 1$ $(1.56 \mathrm{mCi} / \mathrm{l})=37 \mathrm{nmol} / 1$. Unlabelled DHT and all other reagents, unless otherwise stated, were obtained from Merck AG (Darmstadt). A $37 \mu \mathrm{mol} / 1$ solution of DHT was prepared in physiological $\mathrm{NaCl}$ solution/ethan ol $(9+1$, volumes).

Electrophoresis buffer: Na-diethylbarbiturate-ace ta te-HCi, pH 8.2 at $0^{\circ} \mathrm{C}$, ionic strength $\mu=0.1$.

Charcoal suspension: $260 \mathrm{~g} / 1$ Norit A (Serva, Heidelberg), $2 \mathrm{~g} / 1$ Dextran T70 (Pharmacia, Uppsala) in Tris- $\mathrm{HCl}(0.01 \mathrm{~mol} / \mathrm{l}$, $\mathrm{pH} 7.4$ at $20^{\circ} \mathrm{C}$ ).

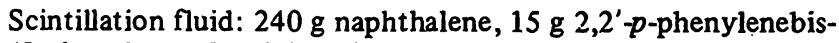
(5-phenyloxazole), $0.15 \mathrm{~g} 2,5$-diphenyloxazole, made up to 3 litres with dioxan/xylene $(21+11)$.

\section{Incubation}

The procedures were carried out at $4^{\circ} \mathrm{C}$. Plasma was diluted $1: 21$ with Tris-HCl-buffer. Tritiated DHT was added, giving a final $\left[{ }^{3} \mathrm{H}\right] \mathrm{DHT}$ concentration of $5.2 \mathrm{nmol} / \mathrm{l}$. In a parallel test tube tritiated DHT together with unlabelled DHT were added to plasma, giving a final concentration of $5.2 \mathrm{nmol} / 1$ for $\left[{ }^{3} \mathrm{H}\right] \mathrm{DHT}$ and $5.2 \mu \mathrm{mol} / 1$ for DHT. Incubation period: 14 hours at $0^{\circ} \mathrm{C}$. In preliminary experiments, plasma was treated with charcoal before the steroid incubation: $0.2 \mathrm{ml}$ of the charcoal suspension was added to $0.22 \mathrm{ml}$ of diluted plasma (diluted $1: 11$ with Tris$\mathrm{HCl}$ buffer). The mixture was stirred overnight at $4^{\circ} \mathrm{C}$. After this period the dextran-coated charcoal was removed by centrifugation at $5000 \mathrm{rpm}$ for 4 minutes, and the supernatant used for further incubation steps.

\section{Agar gel electrophoresis}

This technique was inaugurated by Wagner (9). The apparatus for punching and slicing the gel layer was purchased from the workshop of the Max-Planck-Institut für Zellbiologie (Wilhelmshaven). Preparation of agar/agarose gels: $1.35 \mathrm{~g}$ pure agar (Behringwerke, Marburg) and $0.15 \mathrm{~g}$ agarose (Serva, Heidelberg) were made up to $75 \mathrm{ml} \mathrm{H}_{2} \mathrm{O}$ plus $75 \mathrm{ml}$ electrophoresis buffer, boiled briefly and allowed to gel in a Plexiglas mould. Two gel layers of $95 \times 100 \times 5 \mathrm{~mm}$ were cut out and slid onto $95 \times 95$ $\times 0.6 \mathrm{~mm}$ glass plates, one end of the gel overlapping the plate by $5 \mathrm{~mm}$. The gels can be stored at $4^{\circ} \mathrm{C}$ in a humid chamber for several days. For the application of plasma samples $(40 \mu \mathrm{l}$ per hole), 10 holes are punched at right angles to the direction of separation in the middle of the gel layer, between the anodic and cathodic end.
The glass plates, bearing the gel layers, are placed on a tefloncoated metal block (Hübscher, Hamburg), which is cooled at $-2^{\circ} \mathrm{C}$ by a cryostat K4R (Meßgerätewerk, Lauda). Attachment of the ends of the gels to anode and cathode respectively is by means of filter paper bridges $(140 \times 100 \mathrm{~mm})$, dipping into the electrophoresis buffer. The bridges consist at the cathode of two layers of filter paper MN 866 (Macherey \& Nagel, Düren), at the anode of one filter paper MN 604, underlying the gel end which overlaps the glass plate, followed by one MN 866 and one MN 604 filter paper, the latter covering the gel end by approximately $5 \mathrm{~mm}$. After filling the sample holes with plasma, the electrophoresis (power supply type 121260 , Desaga, Heidelberg) was run 90 minutes at $10 \mathrm{Volt} / \mathrm{cm}$ (circa $130 \mathrm{~mA}, 300 \mathrm{~V}$ ), the temperature in the gèl being $+4^{\circ} \mathrm{C}$. The mètal block and buffer trays are covered by a perspex lid (Hübscher, Hamburg). After electrophoresis, the gel was cut into 10 strips parallel to the direction of separation with a sample-hole in the middle of each strip. The strips were finally divided into $3 \mathrm{~mm}$ wide gel slices at right angles to the direction of separation.

\section{Measurement of radioactivity}

The $3 \mathrm{~mm}$ wide gel slices were deep frozen for 2 hours at $-18^{\circ} \mathrm{C}$ in counting vials in order to facilitate elution of the radioactivity by the scintillation fluid. After addition of the scintillation fluid, the counting vials were shaken for 1-2 hour and then analyzed in a scintillation counter (Packard TriCarb 3390, efficiency $32 \%$ ). Because of the constant ratio to the internal standard, the radioactivity was measured in counts/min.

\section{Calculation of the SHBG-binding capacity}

Under the assumption that SHBG is completely saturated by $\left[{ }^{3} \mathrm{H}\right] \mathrm{DHT}$, the amount of bound $\left[{ }^{3} \mathrm{H}\right] \mathrm{DHT}$ is equal the SHBGbinding capacity. Furthermore, if a mol to mol binding relationship between steroid and SHBG is assumed $(13,14)$, the concentration of SHBG-bound hormone is equal to the SHBG concentration. The SHBG-binding capacity $M$ is calculated by the equation: $M=A \times F+K$, where $A=$ activity (counts/min), estimated by subtracting from the totally bound $\left[{ }^{3} \mathrm{H}\right] \mathrm{DHT}$ in the SHBG peak the background; $\overline{\mathrm{F}}=$ factor, which corrects for efficiency of the scintillation counter, for specific activity of the $\left[{ }^{3} \mathrm{H}\right] \mathrm{DHT}$, and for plasma dilution; $\mathrm{K}=$ factor, which corrects for the dissociation of $\left[{ }^{3} \mathrm{H}\right] \mathrm{DHT}$ from the SHBG during the run. If the SHBG-bound $\left[{ }^{3} \mathrm{H}\right] \mathrm{DHT}$ decreases by $28.5 \%$ per 90 minute the corresponding $\mathrm{K}$ is $40 \%$. (Example: During the run the peak of 1000 counts/min decreases by $28.5 \%$ to 715 counts $/ \mathrm{min}$, i.e. if after a 90 minute run $715 \mathrm{cpm}$ are found, then 285 counts/min (i.e. $40 \%$ of 715 counts $/ \mathrm{min}$ ) must be added in order to obtain a peak value of 1000 counts $/ \mathrm{min}$ ).

SHBG-binding capacity determination according to Deñnis et al. This technique has been described in detail elsewhere (15).

\section{Statistics}

1. Spearman rank correlation was performed when comparing the binding data obtained by the two methods used.

2. The significant differences in SHBG-bind ing capacity between the younger and older group were checked by Student-t-test, assuming a normal distribution of the data.

\section{Results}

When incubating human plasma with tritiated DHT alone, or together with a 1000 -fold excess of unlabelled DHT, binding patterns as shown in figure 1 were obtained by agar gel electrophoresis. The SHBGbound radioactivity was found cathodically (right from the start) in slice numbers $15-18$, while unbound, e.g. free radioactivity was present in slice numbers 19-28. As outlined in Material and Methods, the binding difference of $\left[{ }^{3} \mathrm{H}\right] \mathrm{DHT}$ in slice numbers $15-18$ (shaded area) is taken for the calculation of the SHBG- 


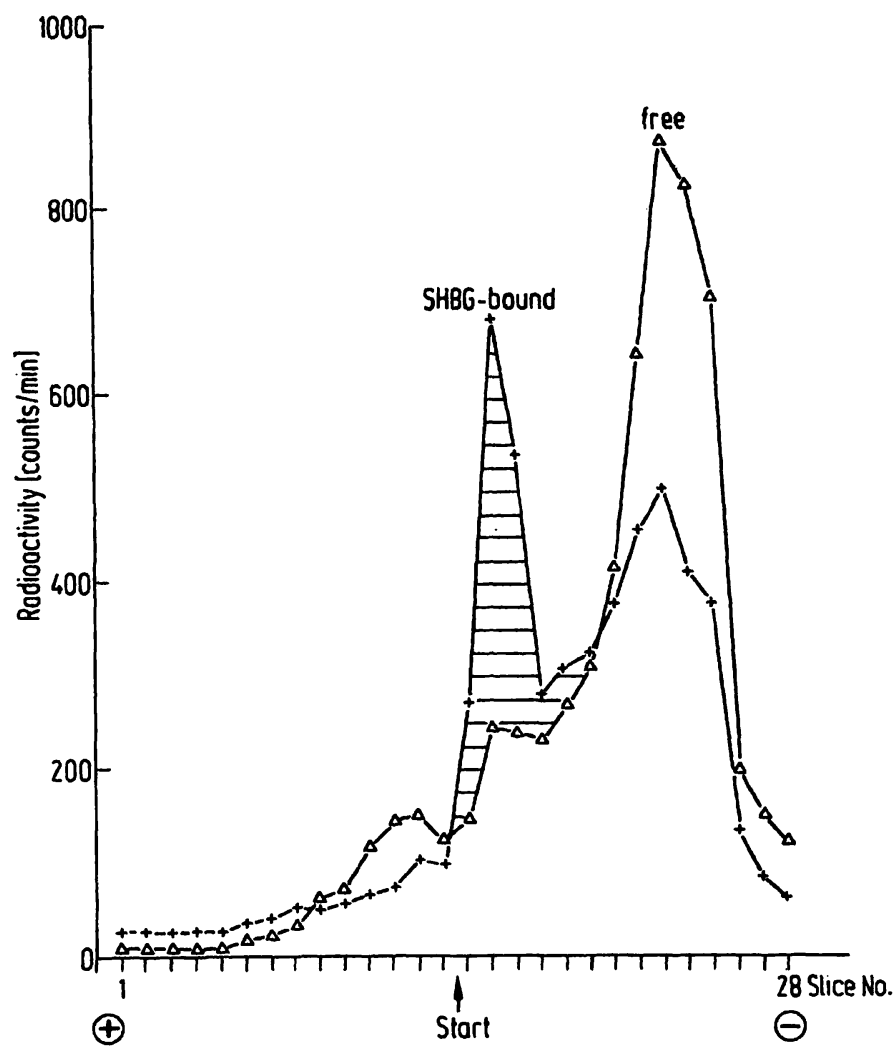

Fig. 1. Binding and displacement of $\left[{ }^{3} \mathrm{H}\right] 5-\alpha$-dihydrotestosterone (DHT) in male plasma, analyzed by agar gel electrophoresis. Plasma (1:21 diluted with Tris-HCl buffer) was incubated for 14 hours at $0^{\circ} \mathrm{C}$ with $5.2 \mathrm{nmol} / 1\left[^{3} \mathrm{H}\right] \mathrm{DHT}$ alone $(+)$ or in the presence of a 1000 -fold excess $(5.2 \mu \mathrm{mol} / 1)$ of unlabelled DHT $(\Delta)$. The peak difference in slice numbers 15-18 (shaded area) indicates the SHBGbound [ $\left.{ }^{3} \mathrm{H}\right] \mathrm{DHT}$.

binding capacity. A small quantity of the displaced radioactivity is shifted to the anodic part of the gel, while the majority is recovered in the free fraction.

Figure 2 shows that the SHBG peak decreases with increasing dilution of the plasma, incubated with a final $\left[{ }^{3} \mathrm{H}\right] \mathrm{DHT}$ concentration of $5.2 \mathrm{nmol} / 1$. In figure 3 it is shown that using constant amounts of $\left[{ }^{3} \mathrm{H}\right] \mathrm{DHT}$ and $\left[{ }^{3} \mathrm{H}\right] \mathrm{DHT}$ plus unlabelled DHT respectively, the SHBG: bound radioactivity decreases linearily with the plasma dilution, indicating that the SHBG-binding is saturated under the experimental conditions used. Also we found that the incubation of $1: 21$ diluted male plasma with increasing concentrations of tritiated DHT $(5.2 \mathrm{nmol} / 1$ $110 \mathrm{nmol} / 1$ ) and tritiated DHT plus unlabelled DHT respectively does not increase the SHBG-bound radioactivity. When analyzing $1: 21$ diluted pregnancy plasma ( 37 th week of gestation) saturation of the SHBG. bound radioactivity was obtained when using $52 \mathrm{nmol} / 1$ [ ${ }^{3}$ H]DHT.

As shown in figure 4, pretreatment of the plasma by an overnight charcoal incubation, in order to remove endogenous steroid from the SHBG, does not lead to a higher binding capacity and was therefore omitted.

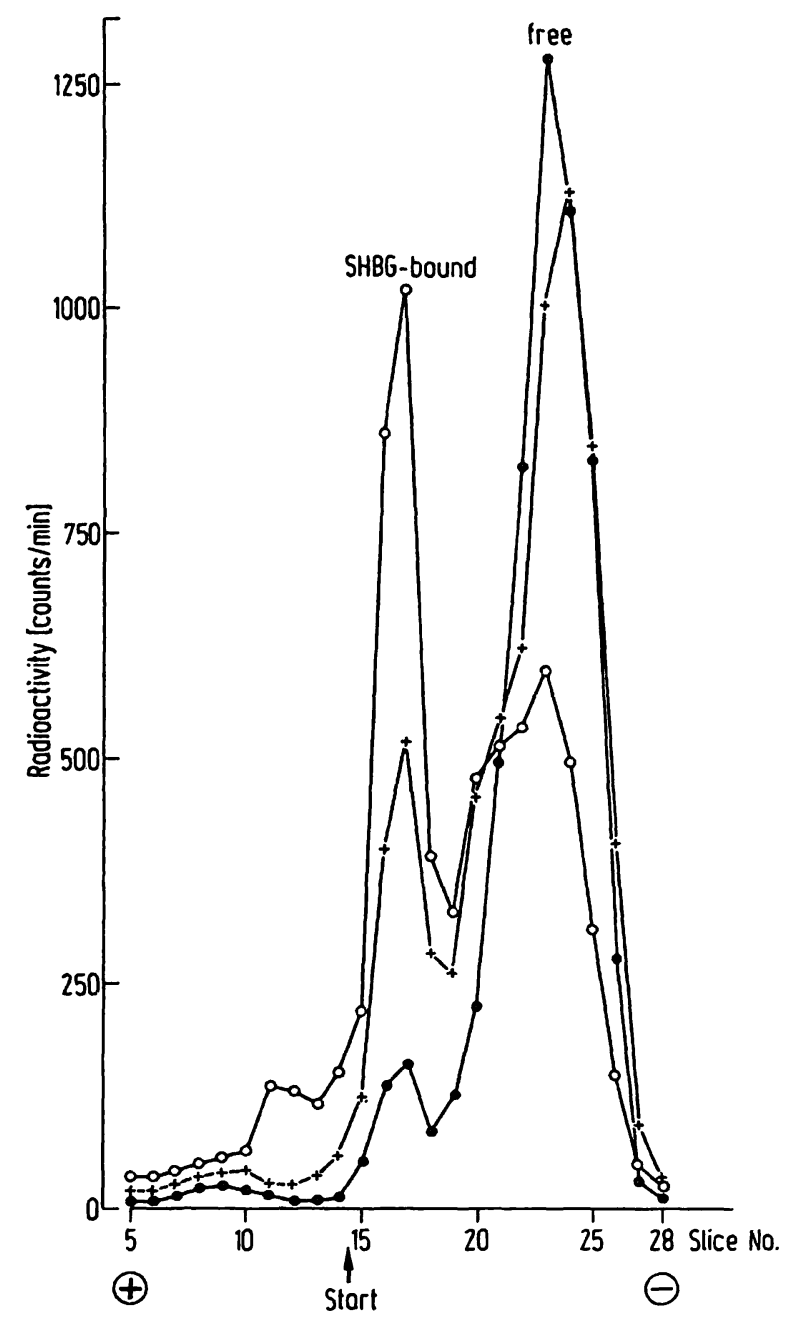

Fig. 2. Binding of $\left[{ }^{3} \mathrm{H}\right] 5 \alpha$-dihydrotestosterone (DHT) in different dilutions of male plasma, analyzed by agar gel electrophoresis. Plasma was diluted $1: 11(0), 1: 21(+)$ and $1: 51(\bullet)$ with Tris- $\mathrm{HCl}$ buffer and incubated with $\left[{ }^{3} \mathrm{H}\right] \mathrm{DHT}$ in a final concentration of $5.2 \mathrm{nmol} / 1$.

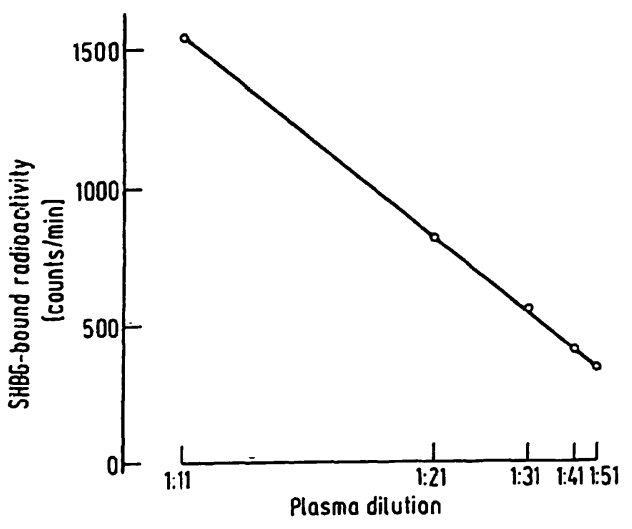

Fig. 3. Relationship between SHBG-bound $\left[{ }^{3} \mathrm{H}\right] 5 \alpha$-dihydrotestosterone (DHT) and plasma dilution. The final concentration of added $\left[{ }^{3} \mathrm{H}\right] \mathrm{DHT}$ was constant $(5.2 \mathrm{nmol} / \mathrm{l})$, and the plasma was diluted with Tris- $\mathrm{HCl}$ buffer. The binding data were obtained by agar gel electrophoresis. Mean values of three experiments are shown with deviation from experimental values of $<5 \%$. 


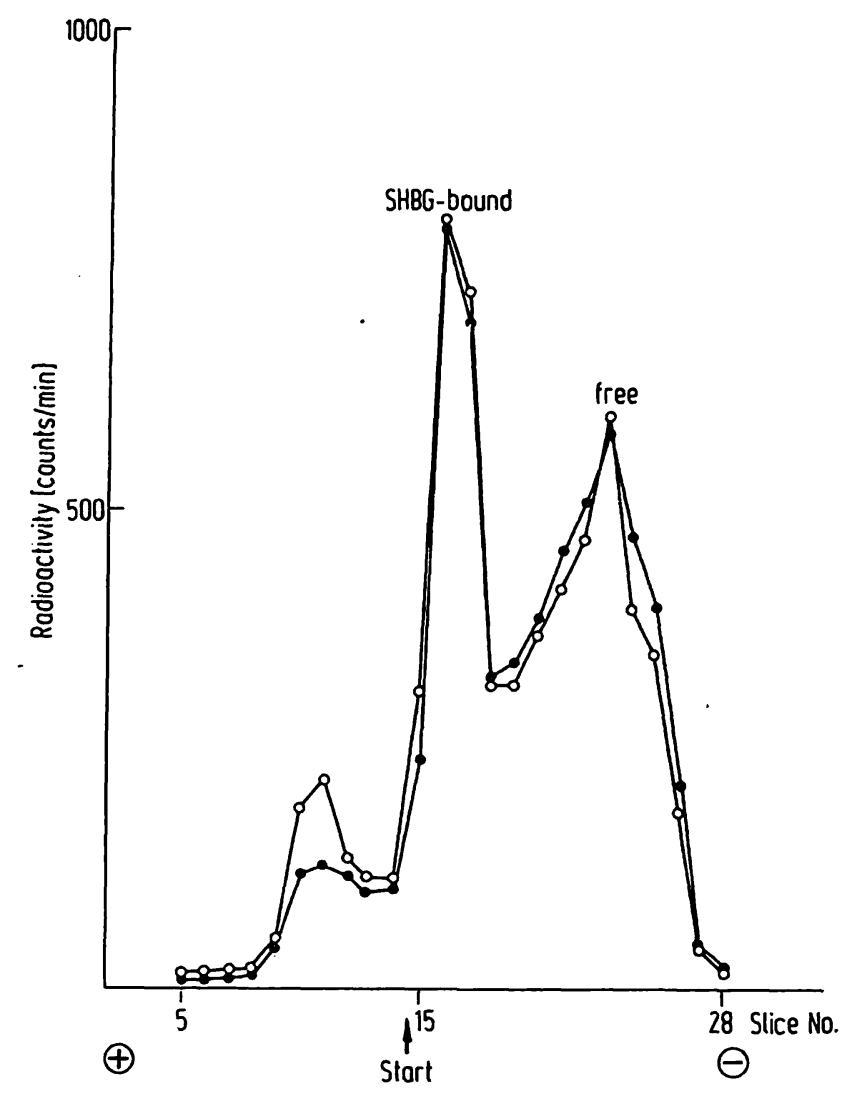

Fig. 4. Binding of $\left[{ }^{3} \mathrm{H}\right] 5 \alpha$-dihydrotestosterone (DHT) to SHBG of plasma, non-treated $(\bullet)$ or treated $(0)$ with charcoal overnight, before $\left[{ }^{3} \mathrm{H}\right] \mathrm{DHT}$ was added (for further details see Material and Methods).

During the electrophoresis, a time-dependent amount of SHBG-bound DHT will be dissociated from SHBG, as shown in figure 5 . The linearity of the time-dependent dissociation is plotted in figure 6 . Two experiments give nearly identical results, the average rate being $19 \%$ per hour. In order to determine the actual SHBG-binding capacity the SHBG-bound DHT after a 90 minute electrophoresis must be corrected for the dissociation rate (see Material and Methods).

The precision of the method was checked by performing 10 determinations of a male plasma sample within one electrophoresis (intra-assay); the coefficient of variation was $3.7 \%$, the inter-assay coefficient of variation being $9.8 \%(n=8)$. Due to the lack of purified SHBG, accuracy could not be determined. An indirect evaluation of the accuracy of the method is shown in figure 7, where 10 male plasma samples were simultaneously analyzed by agar gel electrophoresis and by a method first described by Dennis et al. from this laboratory (15).

In figure 8 the normal range $(\overline{\mathrm{x}} \pm s)$ of the SHBG-binding capacity of 26 blood donors (aged 22-41) is summarized. In table 1 the range is compared with values derived by other techniques.

Plasma of males aged 48-64 shows significantly $(\mathrm{P}<$ $0.02)$ higher SHBG-binding capacities $(48 \pm 10 \mathrm{nmol} / 1)$ than plasma of the younger group. The highest SHBGbinding capacities are found in two pregnancy plasmas, the values being 330 and $400 \mathrm{nmol} / 1$ respectively.

\section{Discussion}

In order to use routinely the method described above as a tool for obtaining relevant values for the plasma SHBG-binding capacity, the SHBG-binding peak must be saturated. Plasma dilution and the amount of $\left[{ }^{3} \mathrm{H}\right]$ DHT added are the two parameters by which saturation
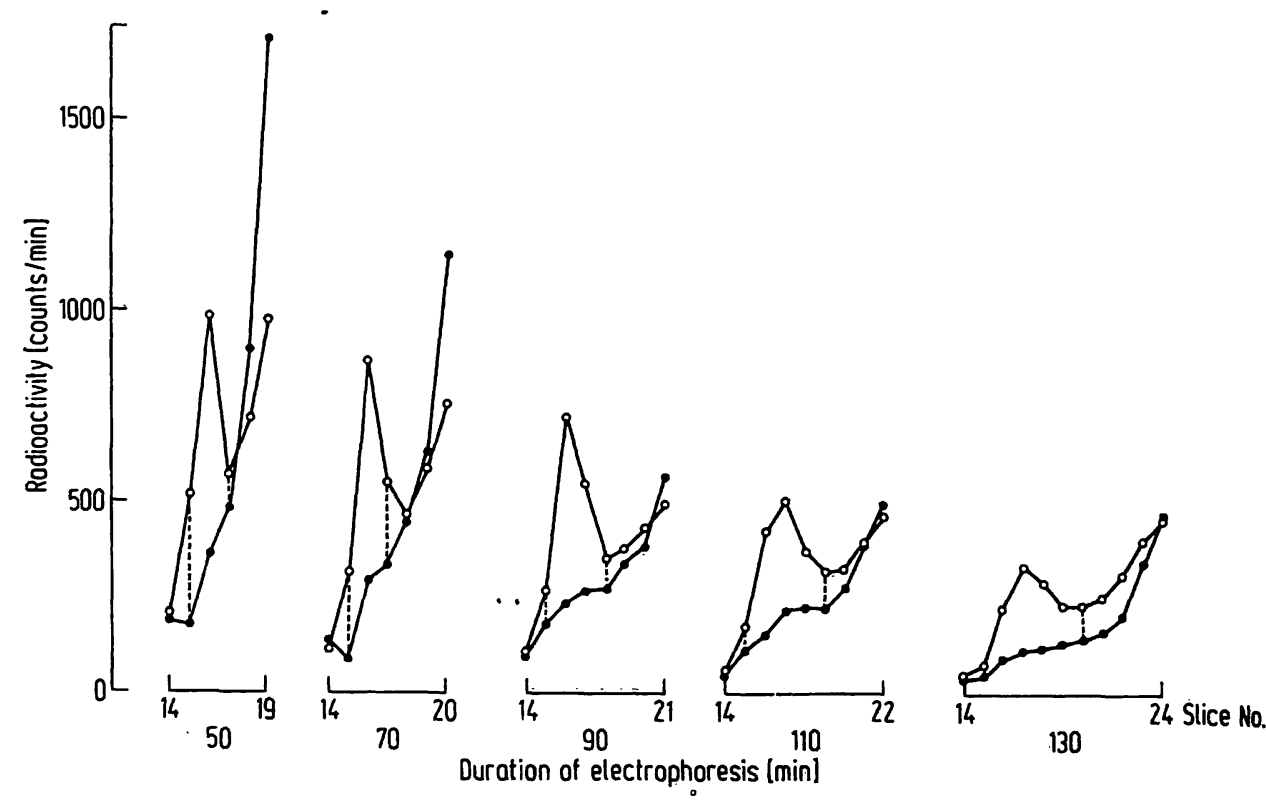

Fig. 5. Dissociation of the SHBG- $\left[{ }^{3} \mathrm{H}\right] 5 \alpha$-dihydrotestosterone (DHT)-binding during agar gel electrophoresis. Male plasma, diluted $1: 21$ with Tris-HCl buffer was incubated with $\left[{ }^{3} \mathrm{H}\right] \mathrm{DHT}$ alone $(0)$ or with $\left[{ }^{3} \mathrm{H}\right] \mathrm{DHT}$ plus a 1000 -fold excess of unlabelled DHT (๑). The binding pattern was analyżed at various running times. Only the SHBG peak is plotted in this figure. 


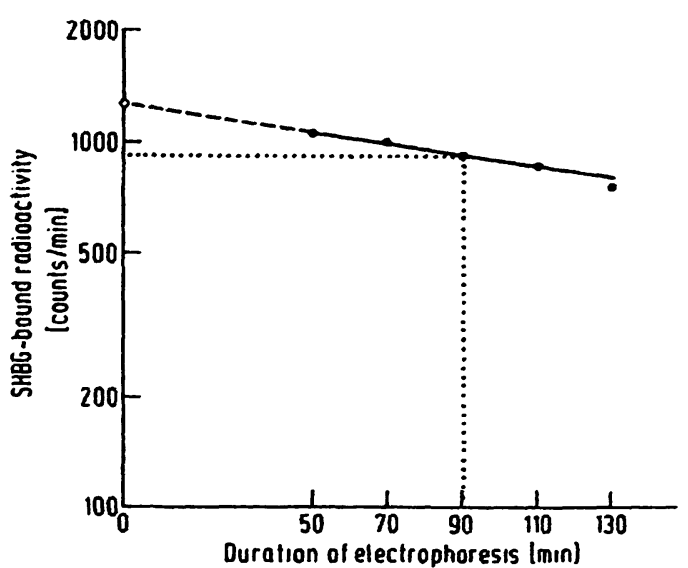

Fig. 6. Dissociation of the SHBG-bound $\left[{ }^{3} \mathrm{H}\right] 5 \alpha$-dihydrotestosterone (DHT) during agar gel electrophoresis. The intercept of the extrapolated broken line with the ordinate indicates the SHBG-bound $\left.\mid{ }^{3} \mathrm{H}\right] \mathrm{DHT}$ at time 0 of the electrophoresis. The dotted lines indicate the measured amount of SHBG bound $\mid{ }^{3} \mathrm{H}$ JDHT at 90 minutes. Mean values of two experiments are shown with deviation from experimental values of $<2 \%$.

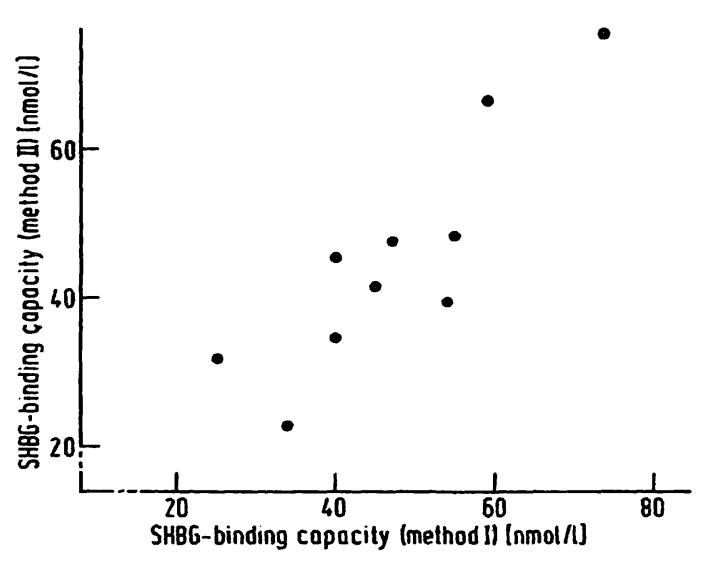

Fig. 7. Spearman rank correlation of SHBG-binding capacities of 10 male plasma samples, analyzed independently by two methods. Method I: agar gel electrophoresis; Method II: technique including ammonium sulphate precipitation and differential dissociation of the SHBG- $\left.-{ }^{3} \mathrm{H}\right] 5 \alpha$-dihydrotestosterone complex. $n=10, r=0.83, p<0.01$.

is obtained. We diluted the male plasma $1: 21$ and incubated it with $5.2 \mathrm{nmol} / 1\left[^{3} \mathrm{H}\right] \mathrm{DHT}$. This concentration of $\left[{ }^{3} \mathrm{H}\right] \mathrm{DHT}$ is about three times higher than the average SHBG-binding capacity in undiluted male plasma. If extremely high $S \mathrm{HBG}$ concentrations are expected, e.g. in pregnancy plasma $(12,16)$, a ten-fold higher $\left[{ }^{3} \mathrm{H}\right] \mathrm{DHT}$ concentration was used to fulfill saturation conditions in a relatively wide range. Wagner \& $\dot{R}$ üffert (12) favoured a plasma dilution of $1: 50$ which gives, in our hands, relatively low binding peaks for male plasma (fig. 2), thus raising the statistical error of the counting rate of radioactivity from $2 \%$ to greater $5 \%$.

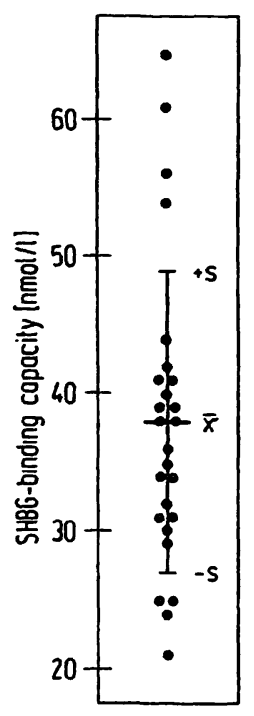

Fig. 8. SHBG-binding capacities in plasma of 26 normal males aged $22-41$. The mean is indicated by $\bar{x} ; s=$ standard deviation.
Tab. 1. SHBG-binding capacities found by various authors in male plasma.

\begin{tabular}{lllll}
\hline & $\overline{\mathrm{x}}$ & $\mathrm{s}$ & $\mathrm{n}$ & age \\
& $(\mathrm{nmol} / \mathrm{l})$ & & & \\
\hline Wagner \& Rüffert (12) & 75 & 15 & 35 & $15-54$ \\
Shanbhag et al.*(8) & 61 & - & - & - \\
Ritzen et al. (6) & 59 & 15 & 5 & - \\
Rudd et al. (24) & 50 & 4 & 10 & $21-37$ \\
Vermeulen et al. (16) & 46 & 4 & 12 & $25-55$ \\
Mickelson \& Petra*(7) & 44 & $0.3 * *$ & - & - \\
Heyns \& DeMoor*(17) & 38 & 13 & 24 & $18-50$ \\
Krieg \& Arning (this & 38 & 11 & 26 & $22-41$ \\
work) & & & 18 & $19-34$ \\
Anderson et al. (18) & 36 & 8 & - & - \\
Rosner (19) & 32 & $2 * *$ & - & $22-44$ \\
Dennis et. al. (15) & 29 & 10 & 13 & - \\
Corvol et al. (5) & 17 & $1 * *$ & 10 & - \\
\hline
\end{tabular}

$\overline{\mathbf{x}}=$ mean; $s=$ standard deviation; $\mathrm{n}=$ number

* = calculated from $\mu \mathrm{g} / 100 \mathrm{ml} 5 \alpha$-dihydrotestosterone binding

** = standard error of the mean

Pretreatment of the plasma with charcoal, in order to remove endogenous steroids, which may occupy SHBGbinding sites, does not raise the binding capacity for $\left[{ }^{3} \mathrm{H}\right] \mathrm{DHT}$. This is in accordance with findings reported elsewhere $(6,19,20)$. Probably, within the 14 hour incubation period, the high excess of $\left[{ }^{3} \mathrm{H}\right] \mathrm{DHT}$ almost completely displaces endogenous androgens from the SHBG. Furthermore, charcoal might eliminate small amounts of SHBG itself from the incubation medium (13), thus masking the possible rise of the binding capacity. However, as shown by Dennis et al. (15), the loss of SHBG by charcoal adsorption is extremely low.

In contrast to the procedure of Wagner \& Rüffert (12), we have introduced a competition step for quantifying the SHBG-binding capacity. As shown in figure 1, a 
relatively high background was found in slice numbers $15-18$ when incubating plasma with $\left[{ }^{3} \mathrm{H}\right] \mathrm{DHT}$ plus unlabelled DHT. If this background is not subtracted the actual SHBG-binding capacity would rise artificially. It should be noted that the displacement curve of figure 1 often displays a shoulder in slice numbers $15-18$, indicating that small amounts of $\left[{ }^{3} \mathrm{H}\right] \mathrm{DHT}$ remain bound to SHBG. However, for routine determination of the binding capacity, this amount (less than $5 \%$ of the total SHBG) can be neglected.

Before this method was used routinely, the dissociation rate of $\left[{ }^{3} \mathrm{H}\right] \mathrm{DHT}$ from the SHBG-binding peak during electrophoresis was determined. The rate of $19 \%$ per hour is in good agreement with $16.5 \%$ found by Wagner $\&$ Rüffert (12). It may be anticipated that this rate is relatively constant, as it will be influenced only by monitored experimental conditions, e.g. electric field etc., but not by the individual plasma. Therefore we took the dissociation rate of $19 \%$ per hour as a constant factor for calculating the $\left[{ }^{3} \mathrm{H}\right] \mathrm{DHT}$ actually bound to SHBG.
The precision of the method is acceptable. The validity has been shown by the significant correlation of the data with the values obtained according to Dennis et al. (15), as well as by the comparison of normal ranges of SHBGbinding capacities in male plasma (table 1): The values of Wagner \& Rüffert (12), also using agargel electrophoresis, are remarkably high. The main reason for this difference from our values might be that background subtraction has not been performed by these authors. The SHBG-binding capacities found in pregnancy plasma are in the range reported by others $(5,7,8,16,17,19)$.

The increase of the SHBG-binding capacity in elderly men has been described by various authors $(15,21,22)$. Consequently, the percentage binding of testosterone to SHBG (23) will increase, amplified by the slightly lower testosterone plasma levels in elderly men (22). The biological implication of these changes lies in the assumption that only unbound plasmatic testosterone is biologically relevant.

\section{References}

1. Mercier, C., Alfsen, A. \& Baulieu, E. E. (1966), Excerpta Med. Intern. Congr. Ser. Nr. 101, 212.

2. Rosenbaum, W., Christy, N. P. \& Kelly, W. G. (1966), J. Clin. Endocrinol. 26, 1399-1403.

3. DeMoor, P., Heyns, W., Baelen, H. van \& Steeno, O. (1968), Excerpta Med. Intern. Congr. Ser. Nr. 157, 159.

4. Lutz, R. A., Märki, H. H. \& Weder, H. G. (1977), J. Clin. Chem. Clin. Biochem. 15, 57-67.

5. Corvol, P. L., Chrambach, A., Rodbard, D. \& Bardin, C. W. (1971), J. Biol. Chem. 246, 3435-3443

6. Ritzen, E. M., French, F. S., Weddington, S. C., Nayfeh, S. N. \& Hansson, V. (1974), J. Biol. Chem. 249, 65976604

7. Mickelson, K. E. \& Petra, P. H. (1974), FEBS Letters 44, 34-38.

8. Shanbhag, V. P., Södergard, R., Carstensen, H. \& Albertsson, P. A. (1973), J. Steroid Biochem. 4, 537-550.

9. Wagner, R. K. (1972), Hoppe Seyler's Z. Physiol. Chem. 353, $1235-1245$.

10. Krieg, M. \& Voigt, K. D. (1977), Acta Endocrinol. (Kbh.) Suppl. 214, 43-89.

11. Krieg, M., Bartsch, W., Herzer, S., Becker, H. \& Voigt; K. D. (1977), Acta Endocrinol. (Kbh.) 86, 200-215.

12. Wagner, R. K. \& Rüffert, W. (1974), Acta Endocrinol. (Kbh.) Suppl. 184, 84 .
13. Pearlman, W. H. (1970), Acta Endocrinol. (Kbh.) Suppl. 147, $225-235$.

14. Rosner, W. \& Smith, R. N. (1975), Biochemistry 14, 48134820.

15. Dennis, M., Horst, H.J., Krieg, M. \& Voigt, K. D. (1977), Acta Endocrinol. (Kbh.) 84, 207-214.

16. Vermeulen, A., Verdončk, L., Straeten, M. van der \& Orie, N. (1969), J. Clin. Endocrinol: 29, 1470-1480.

17. Heyns, W. \& DeMoor, P. (1971), Steroids 18, 709-730.

18. Anderson, D. C., Pepiatt, R., Schuster, L. \& Fisher, R. (1972), J. Endocrinol. 55, XI-XII (Proceedings).

19. Rosner, W. (1972), J: Clin. Endocrinol. Metab. 34, 983988.

20. Tulchinsky, D. \& Chopra, I. J. (1973), J. Clin. Endocrinol. Metab. 37, 873-881.

21. Vermeulen, A., Rubens, R. \& Verdonck, L. (1972), J. Clin. Endocrinol. 34, 730-735.

22. Pirke, K. M: \& Doerr, P. (1973), Acta Endocrinol. (Kbh.) $74,792-800$.

23. Horst, H.-J., Becker, H. \& Voigt, K. D. (1974), Steroids 23, 833-844.

24. Rudd, B. T., Duignan, N. M. \& London, D. R. (1974), Clin. Chim. Acta $55,165-178$.

Priv. Doz. Dr. med. M. Krieg Department of Clinical Chemistry, Medical Clinic University of Hamburg Martinistr. 52

D-2000 Hamburg 20, F.R.Germany 